\title{
Cancer magnitude, challenges and control in the Eastern Mediterranean Region
}

S. Omar, ${ }^{1}$ N.H.M Alieldin ${ }^{2}$ and O.M.N. Khatib ${ }^{2}$

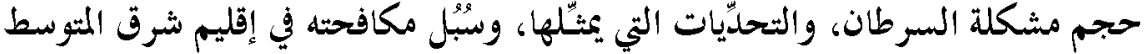

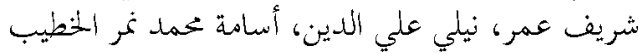

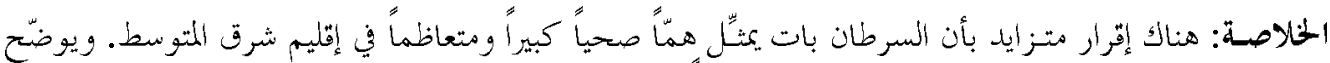

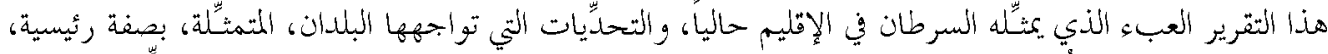

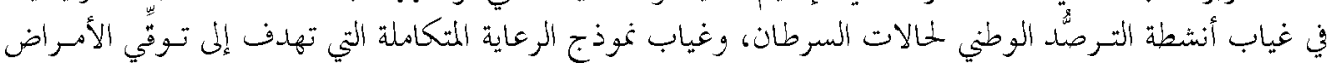

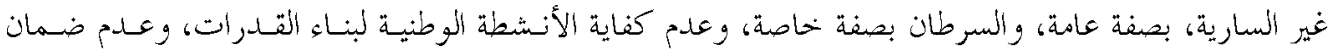

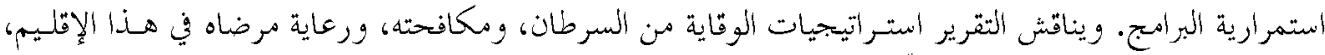

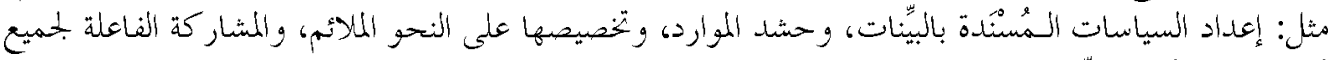

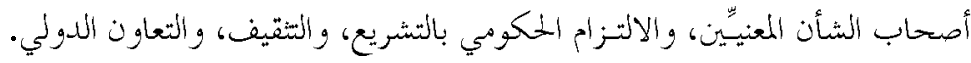

ABSTRACT Cancer is increasingly recognized as a major and growing health concern in the Eastern Mediterranean Region (EMR). This report outlines the current burden of cancer in the Region and the challenges faced by the countries; these are mainly lack of national cancer surveillance, lack of a model of integrated care for noncommunicable disease prevention in general and cancer in particular, inadequate national capacity-building and lack of programme sustainability. Strategies for cancer prevention, control and care in the Region are discussed, such as: the formulation of evidence-based policies, mobilization and appropriate allocation of resources, active participation of all stakeholders, government commitment to legislation, education and international collaboration.

\section{Dimension, défis et maîtrise du cancer dans la Région de la Méditerranée orientale}

RÉSUMÉ Dans la Région de la Méditerranée orientale, le cancer s'affirme chaque jour davantage comme un problème de santé majeur de plus en plus pesant. Ce rapport se propose de délimiter l'impact du cancer dans la Région et les défis que doivent relever les pays, à savoir notamment le défaut de surveillance du cancer au niveau national, l'absence d'un modèle de soins intégrés pour la prévention des maladies non transmissibles en général et du cancer en particulier, l'insuffisance des politiques nationales de renforcement des capacités et le peu de viabilité des programmes. Sont ici discutées les stratégies de prévention et de lutte anticancéreuses ainsi que de prise en charge du cancer dans la Région, par exemple la formulation de politiques factuelles, la mobilisation et l'affectation raisonnée des ressources, la participation active de toutes les parties prenantes, l'implication des instances gouvernementales dans la législation, l'éducation et la collaboration internationale.

${ }^{1}$ National Cancer Institute, Cairo, Egypt.

${ }^{2}$ Noncommunicable Disease Unit, Division of Health Promotion and Protection, WHO Regional Office for the

Eastern Mediterranean, Cairo, Egypt (Correspondence to O.M.N. Khatib: oussamakhatib@gmail.com).

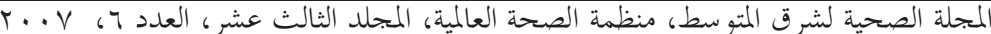




\section{Introduction}

Cancer is the second most common killer in the world today, after cardiovascular disease [1]. According to the World Health Organization (WHO), 13\% of all deaths worldwide are currently caused by cancer [2]. Cancer is and will become an increasingly important factor in the global burden of disease in the decades to come. The estimated number of new cases each year is expected to rise from 11 million in 2002 to 27 million by 2030 [1-4] (Table 1). Approximately $60 \%$ (about 6.5 million) of all these new cases are expected to occur in less developed countries.

In the Eastern Mediterranean Region (EMR) of WHO, cancer is the fourth most common killer and is increasingly recognized as a major heath problem (Figure 1, Table 1) [1-12]. The main factors contributing to the projected increase are the growing proportion of elderly people and the overall reduction in deaths from communicable diseases. Changes in lifestyle have resulted in more exposure to cancer-promoting substances. This, together with the increased prevalence of tobacco use, changes in social and dietary habits, decreased physical activity, and exposure to other environmental risk factors, contributes to the increased cancer morbidity. The EMR is expected to see the greatest increase in cancer incidence in the next 15 years, with an increase between $100 \%$ and $180 \%$ according to projection modelling (Figure 2) [13].

The considerable magnitude of the cancer burden in the EMR was recognized at the 43rd Session of the WHO Regional Committee for the Eastern Mediterranean in 1996, at which a resolution for cancer control and prevention was adopted. In the last 15 years, the WHO Cancer Control Programme has fostered the development of national cancer control programmes as a primary intervention strategy for a comprehensive and cost-effective approach at the country level.

This paper presents an overview of the current cancer situation in the Region and the actions needed to tackle the growing burden. Data for this report were obtained from the following sources. National population-based registries [7,14-17], regional population-based registries [18,19,20-24], GLOBOCAN - 2002 IARC for countries with hospital-based registries (Morocco, Sudan and Yemen) or those lacking any form of cancer registry (Somalia, Djibouti and Afghanistan) [25].

\begin{tabular}{|c|c|c|c|c|}
\hline & World 2002 & World 2030 & EMR 2002 & EMR 2030 \\
\hline Population census & 6229629168 & 8206457382 & 492721000 & $649074572^{a}$ \\
\hline Absolute incidence & 11000000 & 27000000 & 529000 & $1953714^{b}$ \\
\hline Deaths & 7000000 & 17000000 & 272000 & 1003145 \\
\hline Prevalence & 25000000 & 75000000 & 1017441 & 3758142 \\
\hline
\end{tabular}

المجلة الصحية لشرق المتوسط، منظمة الصحة العالمية، المجلد الثالث عشر، العدد Y، V... 


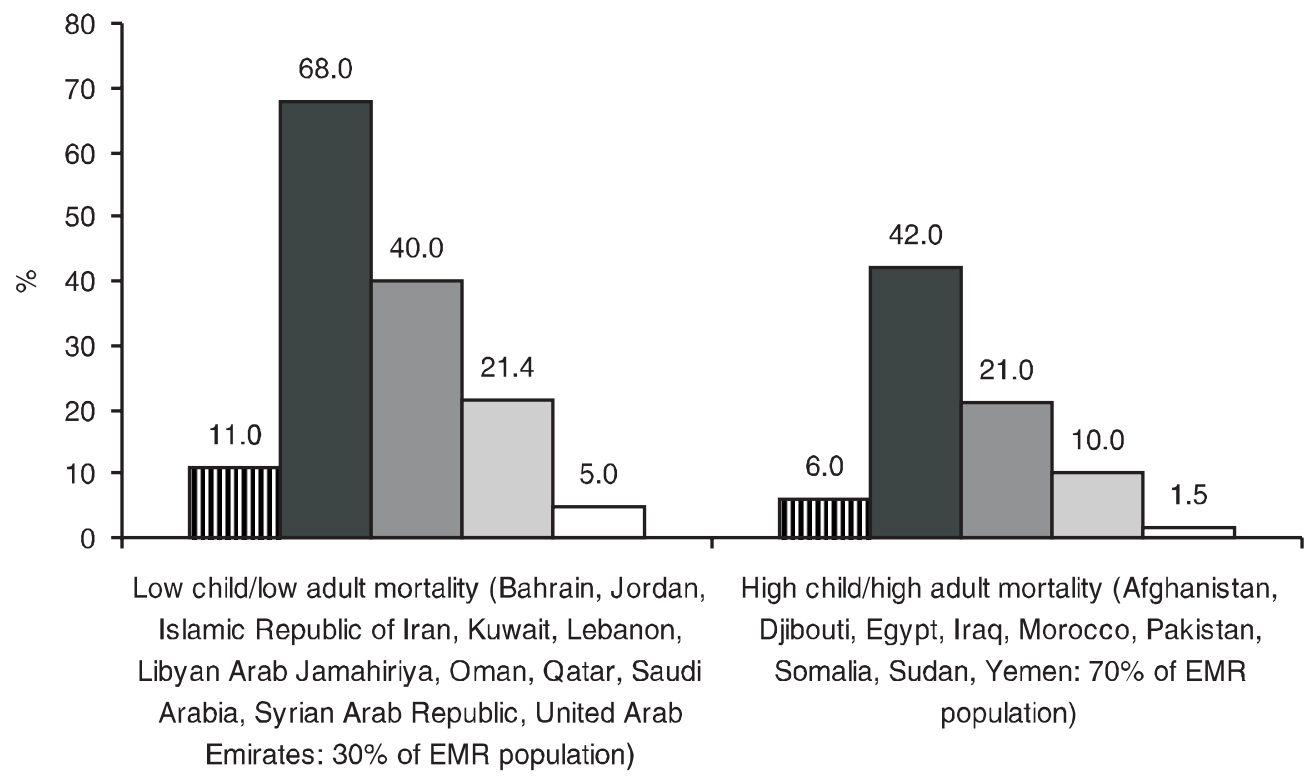

II Cancer

$\square$ Cardiovascular disease

$\square$ Diabetes
Noncommunicable diseases (total)

$\square$ Ischaemic heart disease

Figure 1 Deaths by cause, Eastern Mediterranean Region (EMR), 2002 [12,26,30,31]

\section{Burden of cancer in EMR countries}

The burden of cancer can be described with respect to incidence (newly diagnosed cases), prevalence (new and old cases), mortality, or survival estimates. In the EMR, the absolute incidence of cancer was more than half a million new cases/year (528 729 new cases) identified through national/local cancer registries or estimated from other sources (Table 1) [1,2,6-8,14,18-23,26-28]. The crude incidence of cancers in males was found to range from $35.1 / 10^{5}$ population/ year in Saudi Arabia to $140 / 10^{5}$ population/ year in Lebanon with a weighted average of $97.7 / 10^{5}$ population. In females it ranged from 33.3 to $147.7 / 10^{5}$ population with a weighted average of $95.83 / 10^{5}$ population in the same 2 countries. The male to female ratio was 1.02. Lung cancer and breast cancer are responsible for the greatest number of deaths in the Region (Figure 3). In males, lung cancer was the foremost in one-third of EMR countries and 2 nd to 4 th in 8 countries $(38 \%)$. In nearly all EMR countries, breast cancer constituted a public health problem. In women breast cancer was the leading cancer in all countries, except Somalia and Djibouti [1-4,8-10,20-29]. Tables 2 and 3 show the 5 commonest cancers in males and females in EMR countries. 


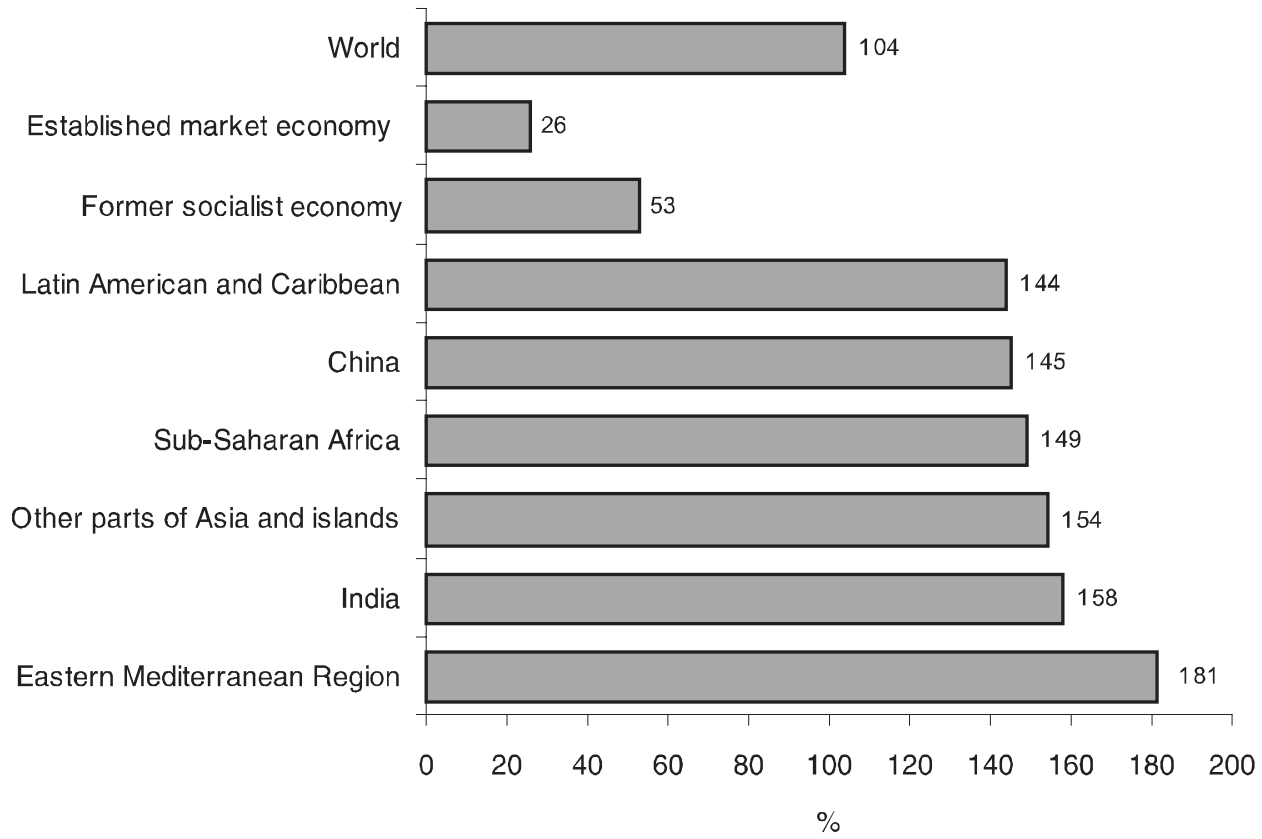

Figure 2 Increase in deaths from cancer (\%) [13]

\section{Cancer data and evidence}

Throughout the Region, reliable data on cancer mortality are lacking. Few registries posses published incidence data and amongst those available, source and citation vary greatly (Figure 4). After extensive and systematic review, data on incidence were reported via national registries in 8 of 21 of EMR countries, and via local or regional cancer registries in 7 countries. Although local cancer data are important in order to develop and evaluate control measures against cancer, up to the end of 2006, 6 countries in the Region had no local or national cancer registries. In addition, many lacked financial or technical resources to collect good quality, complete and timely data.

\section{Cancer control}

Although some progress in cancer control has been made, many EMR countries face constraints which must be overcome to improve cancer control. Indeed, despite rapid wealth and transformation of many countries in the Middle East chronic disease risk and mortality profiles have increased, especially in cancer [24]. Lack of national cancer control plans in most countries is a serious public health problem. Nearly all health systems in the Region are centralized, mainly curative and hospital-based. Primary care is not well developed and public health initiatives are very limited. While there are effective strategies for the 


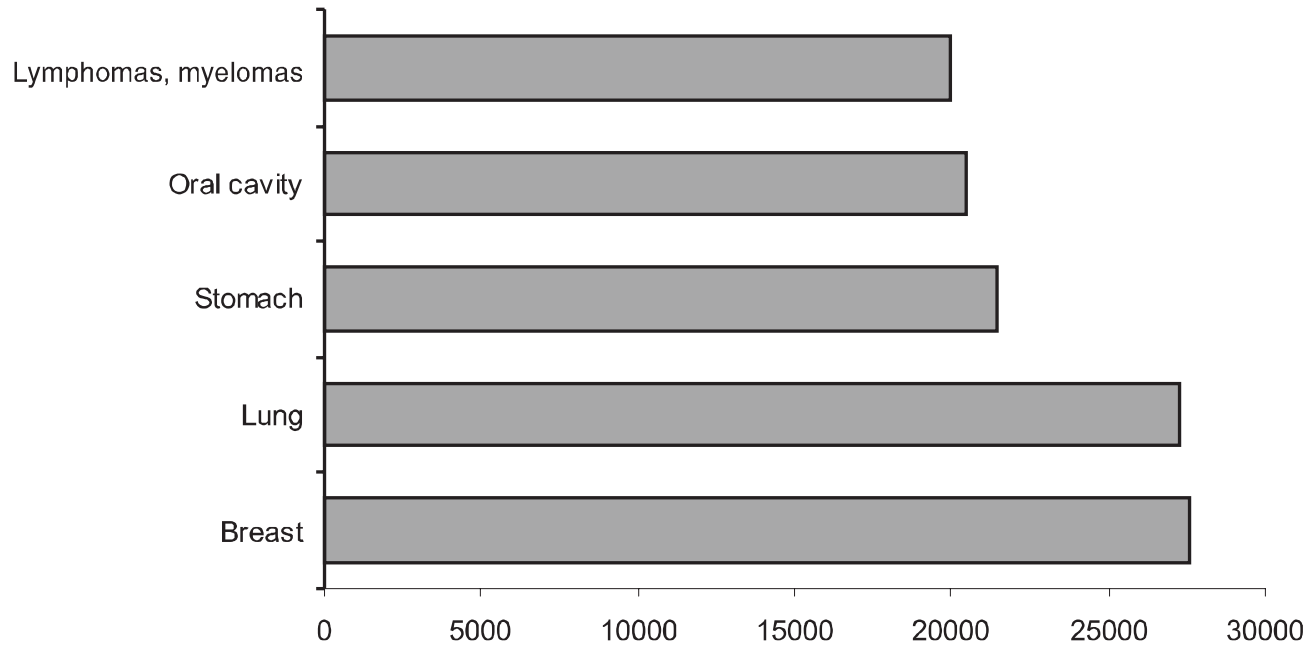

Figure 3 Top 5 cancer causes of deaths in the Eastern Mediterranean Region, 2002 [25]

pain relief and the provision of palliative care in most EMR countries, even in lowincome ones, there is little evidence of prevention both at the population level and among high-risk groups. For example, none of the countries has a call and recall system for the early detection of cervical and breast cancer. Despite some efforts to re-orient the health systems from primarily "curative" to more "preventive", progress has not been significant in most of the countries.

\section{Challenges for the Region}

The political obsession with creating a surplus of hospitals coupled with a lack of leadership within the health services has undermined the ability of governments to predict the impending cancer epidemic. Various WHO studies on cancer services in the EMR have identified common barriers to developing effective cancer control and prevention plans [32]. The principal barriers for cancer prevention and control in EMR include:

- Lack of a clear and well-documented public health policy for all noncommunicable diseases (NCDs), including cancer, in most of EMR countries.

- Lack of political support to develop legislations and regulations to:

- Build up and enhance cancer registries;

- Control tobacco, which alone could prevent one-third of cancers in many of EMR countries;

- Endorse WHO's global strategy on diet, physical activity and health (DPAS).

\section{WHO cancer control strategy}

As a response to the cancer epidemic and following the adoption of the resolution on cancer prevention and control (WHA58.22) 
Table 2 The 5 most common cancer sites in males by country in the Eastern Mediterranean Region $[1,2,6-8,14,18-23,25-29]$

\begin{tabular}{|c|c|c|c|c|c|}
\hline Country & First & Second & Third & Fourth & Fifth \\
\hline Afghanistan ${ }^{a}$ & Stomach & Lung & Oesophagus & Oral cavity & Colorectal \\
\hline Bahrain & Lung & Prostate & Bladder & Colorectal & Stomach \\
\hline Djibouti ${ }^{a}$ & Liver & Oesophagus & Prostate & Kaposi sarcoma & $\mathrm{NHL}$ \\
\hline Egypt & Bladder & Liver & NHL & Lung & Leukaemia \\
\hline Iran (Islamic Republic of) & Stomach & Oesophagus & Colorectal & Skin & Prostate \\
\hline Iraq & Lung & Bladder & Larynx & NHL & Prostate \\
\hline Jordan & Lung & Bladder & Colorectal & NHL & Prostate \\
\hline Kuwait & Colorectal & Prostate & Lung & Liver & NHL \\
\hline Lebanon & Lung & Bladder & Larynx & Leukaemia & Prostate \\
\hline Libyan Arab Jamahiriya & Bladder & Lung & Prostate & Colorectal & Liver \\
\hline Morocco $^{a}$ & Lung & Bladder & Prostate & Stomach & Colorectal \\
\hline Oman & $\mathrm{NHL}$ & Stomach & Prostate & Lung & Colorectal \\
\hline Pakistan & Lung & Oral cavity & Larynx & Bladder & Prostate \\
\hline Qatar & Bladder & Liver & Colorectal & NHL & Prostate \\
\hline Saudi Arabia & Liver & Colorectal & $\mathrm{NHL}$ & Lung & Prostate \\
\hline Somalia ${ }^{a}$ & Liver & Oesophagus & Prostate & NHL & Stomach \\
\hline Sudan & Oral cavity & Prostate & Oesophagus & $\mathrm{NHL}$ & Liver \\
\hline Syrian Arab Republic & Bladder & Leukaemia & Lung & NHL & Colorectal \\
\hline Tunisia & Lung & Skin & Bladder & Prostate & Colorectal \\
\hline United Arab Emirates & Colorectal & Lung & Stomach & Prostate & $\mathrm{NHL}$ \\
\hline Yemen $^{a}$ & Liver & $\mathrm{NHL}$ & Colorectal & Oesophagus & Stomach \\
\hline
\end{tabular}

[33] at the 58th World Health Assembly in May 2005, the Director-General has recently approved the development of various activities for cancer prevention and control.

The aim of the WHO cancer control strategy is to "strengthen and accelerate the translation of cancer control knowledge into public health action. The focus is placed on countries to ensure the reduction of cancer cases and the improvement of the quality of life of patients and their families" [34].

\section{WHO stepwise approach for cancer prevention and care}

WHO has outlined a stepwise framework that ministries of health can use to create a policy and regulatory environment in which other sectors can operate successfully $[1,2,27]$. The guidance and recommendations provided may be used by policy-makers and planners at the national and sub-national levels. This approach includes the following elements. 
Table 3 The 5 most common cancer sites in females by country in the Eastern Mediterranean Region $[1,2,6-8,14,18-23,25-29]$

\begin{tabular}{|c|c|c|c|c|c|}
\hline Country & First & Second & Third & Fourth & Fifth \\
\hline Afghanistan ${ }^{a}$ & Breast & Stomach & Oesophagus & Cervix & Ovary and uterus \\
\hline Bahrain & Breast & Thyroid & Ovary and uterus & Lung & Stomach \\
\hline Djiboutia & Cervix & Breast & Liver & Oesophagus & Ovary and uterus \\
\hline Egypt & Breast & $\mathrm{NHL}$ & Liver & Leukaemia & Bladder \\
\hline \multicolumn{6}{|l|}{ Iran (Islamic } \\
\hline Republic of) & Breast & Ovary and uterus & Stomach & Colorectal & Oesophagus \\
\hline Iraq & Breast & Bladder & Lung & NHL & $\mathrm{HL}$ \\
\hline Jordan & Breast & Colorectal & Ovary & Lymphoma & Leukaemia \\
\hline Kuwait & Breast & Colorectal & Cervix & Thyroid & $\mathrm{NHL}$ \\
\hline Lebanon & Breast & Cervix & Uterus & Leukaemia & Brain and CNS \\
\hline \multicolumn{6}{|l|}{ Libyan Arab } \\
\hline Jamahiriya & Breast & Uterus & Bladder & Colorectal & Leukaemia \\
\hline Morocco $^{a}$ & Breast & Cervix & Colorectal & NHL & Ovary and uterus \\
\hline Oman & Breast & Leukaemia & Cervix & Thyroid & NHL \\
\hline Pakistan & Breast & Oral cavity & Cervix & Oesophagus & Lymphoma \\
\hline Qatar & Breast & Uterus & Thyroid & $\mathrm{NHL}$ & Cervix \\
\hline Saudi Arabia & Breast & Thyroid & Colorectal & NHL & Skin \\
\hline Somalia ${ }^{a}$ & Cervix & Breast & Liver & Oesophagus & Ovary and uterus \\
\hline Sudan ${ }^{a}$ & Breast & Cervix & Oral cavity & Oesophagus & Ovary and uterus \\
\hline Syrian Arab Republic & Breast & Cervix & Leukaemia & Colorectal & Thyroid \\
\hline Tunisia & Breast & Colorectal & Bladder & Uterus & Leukaemia \\
\hline United Arab Emirates & Breast & Thyroid & Ovary & Cervix & Skin \\
\hline Yemen $^{a}$ & Breast & Cervix & Oesophagus & Oral cavity & NHL \\
\hline
\end{tabular}

Ranking was done according to age standardized rate $/ 10^{5}$ and, when equal, by relative frequency.

aln these countries, cancer site ranking was based on estimated rates.

NHL = non-Hodgkin lymphoma.

$H L=$ Hodgkin lymphoma.

CNS = central nervous system

- Provision of a unifying framework for cancer prevention and control by governments that will ensure that actions at all levels and by all sectors are mutually supportive.

- Development of integrated prevention and control strategies - focusing on the common risk factors and cutting across specific diseases. Such strategies have been found to be the most effective.
- Institution of a comprehensive public health action that combines interventions for the whole population and for individuals.

- Implementation of those activities that are most feasible first, given that most countries will not have the immediate resources to do everything that would ideally be done. 
- Promotion of intersectoral interaction at all stages of policy formulation and implementation because major determinants of the cancer burden lie outside the health sector.

- Establishment of locally relevant and explicit milestones for each step and at each level of intervention, with particular focus on reducing health inequalities.

\section{Strategies for EMR countries}

More than $30 \%$ of cancers can be prevented and controlled by using available knowledge. However, without national strategic action, deaths from cancer are expected to increase globally by $17 \%$ between 2005 and $2015[1,2,26,27]$.

There are several problems facing countries of the Region which include: lack of national cancer surveillance and harmonization of monitoring and surveillance methodologies; absence of linkage of cancer mortality data with NCD prevention and control, and lack of availability of an integrated care model for NCD prevention in general and cancer in particular; inadequate national capacity-building; and a lack of programme sustainability.

EMR states thus need to develop and adopt the following strategies and activities to tackle effectively and efficiently cancer prevention and care in their countries.

\section{Estimate population need and advocate for action}

Many countries of the Region do not have a surveillance system for cancer. Knowledge of cancer risk factors is important for predicting the burden of cancer in populations and for identifying potential interventions to reduce such burdens. The World Health Report 2002 [9] identified 8 risk factors that contribute the most to mortality and morbidity that can be changed through primary intervention and that can be easily measured in populations. These are tobacco, alcohol use, physical inactivity, low fruit/vegetable intake, obesity, raised blood pressure, raised cholesterol and diabetes.

\section{Develop national public health policies, strategies and plans for cancer prevention and care and capacity-building}

As $30 \%$ of cancer can be prevented and controlled using available knowledge, a comprehensive and integrated approach is required at the country level, led by the government, and with the full participation of the community. The population-wide approach aims to reduce the risks in the entire population. Cancer can be reduced by small reductions in the average population levels of several known risk factors, such as tobacco consumption and unhealthy diet. Population-wide and individual approaches are complementary and together provide a continuum of interventions. Countries of the Region need to set strategies for developing a model of integrated care for cancer prevention and national capacity-building.

Seventy per cent of EMR countries are low-resource countries and they need to focus on areas where the needs are greatest and there is potential for success. National strategies need to consider priority status for cancer prevention strategies and direct special attention to combat infections that may promote cancer development, such as schistosomiasis and hepatitis B. In areas of endemicity for liver cancer, hepatitis B vaccination should be integrated with other vaccination programmes.

المجلة الصحية لشرق المتو سط، منظمة الصحة العالمية، المجلد الثالث عشر، العدد ب، V... 


\section{Promote and implement community participation in prevention and care of cancer}

The community approach in cancer prevention can be generalized and is costeffective, can diffuse information well, and can influence environmental and institutional policies that relate to the health status of the population. Close collaboration between those implementing the community approach and the national health authorities is important to sustain the programme and for influencing policy development in regard to health.

For the cost-effective approach, all efforts to facilitate the role of the community should enable the individuals and communities to be actively involved to control the factors affecting their health. Education, public health policy and environmental support are complementary approaches to health promotion.

\section{Implement priority actions for palliative care}

WHO recommends implementing comprehensive palliative care programmes to improve the quality of life of patients with cancer and their families $[1,2,27]$. Awareness among public health professionals that cancer pain should be properly controlled needs to be promoted and the WHO essential palliative care medications should be made available. In low resource settings, it is important to ensure that minimum standards for pain relief and palliative care are progressively adopted at all levels of care. Home-based care is generally the best way to achieve good quality care and coverage in countries with strong family support and poor health infrastructure.

\section{Implement national cancer control programmes}

Implementation of national cancer control programmes, tailored to the socioeconomic and cultural context, should allow countries to translate current knowledge into action. The overall aims of a national cancer control programme are to reduce the incidence and mortality of cancer, and improve overall survival and quality of life of cancer patients and their families. National cancer control programmes should aim to: prevent future cancers; diagnose cancers early; provide curative therapy; ensure freedom from suffering; and reach all members of the population.

\section{Conclusion}

Cancer control and care in the EMR are a challenging task, nationally and regionally. Advocacy is needed to raise awareness and create a climate for resource mobilization. Two key messages for advocacy are: a) NCDs are a major disease burden in the Region and b) $30 \%$ of cancers are preventable by using available knowledge, and the solutions are effective and highly cost-effective. The establishment of a national cancer control programme, tailored to the socioeconomic and cultural context, should allow countries to translate the present knowledge into action. Implementation of the necessary measures for cancer prevention and care requires the formulation of evidencebased policies, the mobilization and appropriate allocation of resources, the active participation of all stakeholders and government commitment to legislation, education, and international collaboration in support of cancer control and prevention.

\section{References}

1. National cancer control programmes: policies and managerial guidelines, 2nd

ed. Geneva. World Health Organization, 2002. 
2. Cancer. World Health Organization website (http://www.who.int/cancer/en/, accessed 28 May 2007).

3. Parkin DM et al., eds. Cancer incidence in five continents, Vol. VIII. Lyon, International Agency for Research on Cancer, 2002 (IARC Scientific Publications No. 155)

4. Pisani P, Bray F, Parkin DM. Estimates of the worldwide prevalence of cancer for twenty-five sites in the adult population. International journal of cancer, 2002 , 97:72-81.

5. Sankaranarayanan R, Black RJ, Parkin DM, eds. Cancer survival in developing countries. Lyon, International Agency for Research on Cancer, 1999 (IARC Scientific Publications No. 145).

6. Adib SM et al. Cancer in Lebanon: an epidemiology review of the American University of Beirut Medical Center Tumor Registry (1983-1994). Annals of epidemiology, 1998, 8:46-51.

7. GCC Cancer Incidence 2000. Riyadh, Gulf Center for Cancer Registration, 2000.

8. Mohagheghi M, Mosavi-Jarrahi A. The 3rd Annual Report of Tehran Metropolitan Area Cancer Registry. Tehran, The Cancer Institute Research Center, 2002 (Publication No. 14).

9. World Health Report, 2002. Reducing risks, promoting healthy life. Geneva, World Health Organization, 2002.

10. Danaei G et al. Comparative Risk Assessment Collaborating Group (Cancers). Causes of cancer in the world: comparative risk assessment of nine behavioural and environmental factors. Lancet, 2005 , 366(9499):1784-93.

11. Parkin DM et al. Global cancer statistics 2002. CA: a cancer journal for clinicians, 2005, 55(2):74-108.

12. Demographic and health indicators for countries of the Eastern Mediterrane- an. Cairo, WHO Regional Office for the Eastern Mediterranean, 2005 (WHO-EM/ HST/200/E).

13. Rastogi T, Hildesheim A, Sinha R. Opportunities for cancer epidemiology in developing countries. Nature review. Cancer, 2004, 4:904-17.

14. Incidence of cancer in Jordan 2002 (http:// seer.cancer.gov/publications/mecc/, accessed 12 June 2007)

15. Kuwait National Cancer Registry 2004.

16. Cancer incidence in Oman 2004 (http://www.moh.gov.om/nv_menu. php?fNm=reports/report.htm, accessed 12 June 2007).

17. Lebanon National Cancer Registry 2002 (http://www.leb.emro.who.int/ncd/cancer2002.pdf, accessed 12 June 2007).

18. Bhurgri Y. Karachi Cancer Registry Data-implications for the National Cancer Control Program of Pakistan. Asian Pacific journal of cancer prevention, 2004 , 5(1):77-82.

19. Sadjadi A et al. Cancer occurrence in Iran in 2002, an international perspective. Asian Pacific journal of cancer prevention 2005, 6(3):359-63.

20. Cancer profile in Gharbia - Egypt. Methods and results 1999. Cairo, Middle East Cancer Consortium and Ministry of Health and Population, 2002.

21. Parkin DM et al. Cancer in Africa. Prevention and epidemiology. Lyon, International Agency for Research on Cancer, 2003 (IARC Scientific Publication No. 153).

22. Cancer in Mosul, 2003. Incidence and mortality. Results of Mosul Cancer Registry, 1st ed. Mosul, Mosul Continuing Medical Education Centre, 2004 (Book Series 22).

23. Mzayek F et al. Neoplastic diseases in Aleppo, Syria. European journal of cancer prevention, 2002, 11:503-7.

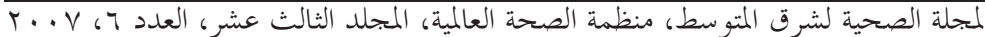


24. Benghazi Cancer Registry (http://www. cancerlibya.com, accessed 12 June 2007).

25. Globocan 2002 (http://www-dep.iarc.fr/, accessed 28 May 2007).

26. WHO Regional Office for the Eastern Mediterranean. Eastern Mediterranean approach to noncommunicable diseases website (http://www.emro.who.int/ncd/, accessed 29 May 2007).

27. Preventing chronic diseases: a vital investment: WHO global report. Geneva, World Health Organization, 2005 (http://whqlibdoc.who.int/publications/2005/9241563001_eng.pdf (File size: 7436 KB, accessed 29 May 2007).

28. Bawazir AA, AbdulHamid G, Morales E. Available data on cancer in the southeastern governorates of Yemen. Eastern Mediterranean health journal, 1998, 4:107-13.

29. Priorities in health. Disease control priorities project. Washington DC, The World Bank, 2006.
30. The SuRF Report 2: Surveillance of chronic disease risk factors: country level data and comparable estimates. Geneva, World Health Organization, 2005 (http:// www.who.int/ncd_surveillance/infobase/ web/surf2/start.html, accessed 28 May 2007).

31. Murray $\mathrm{CH}$, Lopez AD, eds. The global burden of disease. Boston, Harvard School of Public Health. 1996.

32. Cancer prevention and control. Alexandria, World Health Organization Regional Office for the Eastern Mediterranean, 1997 (EMRO Technical Papers series, No.2).

33. WHA58.22. Cancer prevention and control (http://www.who.int/gb/ebwha/pdf_files/ WHA58/WHA58_22-en.pdf, accessed 12 June 2007).

34. WHO Cancer Control Strategy (http:// www.who.int/cancer/media/strategy/en/, accessed 29 May 2007). 